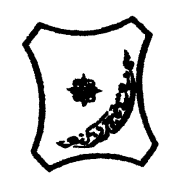

Bayero Journal of Pure and Applied Sciences, 10(2): 305 - 314

Received: November, 2017

Accepted: December, 2017

ISSN $2006-6996$

\title{
DISTRIBUTION PATTERN OF SOME HEAVY METALS IN THE DUST PARTICULATES OF FUNTUA TEXTILE LIMITED, KATSINA, NIGERIA
}

\author{
*Uba, S., Dallatu, Y. A. and Abdulkadir, S. \\ Department of Chemistry, Ahmadu Bello University, PMB 810000, Zaria, Nigeria \\ *Corresponding author: saniuba10@yahoo.com
}

\begin{abstract}
The sequential extraction of $\mathrm{Cd}, \mathrm{Cr}, \mathrm{Cu}, \mathrm{Ni}$, and $\mathrm{Pb}$ in industrial dust particulates collected in ten different sections/Departments of Funtua textile limited and the control site from Dikke village was carried out in order to ascertain the percentage of bioavailable fractions. Analyses of metals in the extracts were done using Flame Atomic Absorption Spectrometry (FAAS). The sequential extractions showed that significant amount of Cu25.87( $\left.O_{1}\right)$ to $92.73 \%\left(E_{1}\right)$ was associated with non-residual and0.09 $\left(E_{1}\right)$ to $56.94 \%\left(\mathrm{O}_{2}\right)$ organic bound fractions; similarly, Cd was also associated with the nonresidual fractions across the sites with values $42.22\left(W_{2}\right)$ to $97.78 \%\left(E_{2}\right)$. Cr and Ni exhibited the highest percentage of $73.46\left(W_{1}\right)$ to $100.00 \%\left(W_{2}\right)$ and $23.64\left(E_{2}\right)$ to $77.26 \%\left(S_{1}\right)$, respectively. Pb in the particulate dust samples was significant/y associated with the non-residual fraction and carbonate bound fraction with range of $21.71(D)-61.68\left(S_{2}\right) \%$ across the sites. This study revealed contamination of the particulates dust especially with $\mathrm{Cu}, \mathrm{Cr}$ and Pb; this implies health risks to human, living or carrying out daily activities along the corridors of this industry.

Keywords: Flame Atomic Absorption Spectrometry, Funtua textile, Heavy metals, Particulates dust, Sequential extraction
\end{abstract}

\section{INTRODUCTION}

Soils are the reservoir for many materials; beneficial and harmful (Odoh et al., 2011). These include biological, chemical as well as heavy metals. Total metal content of soils is useful for most geochemical works but often the speciation (bioavailability) of these metals are more important to the environmentalist (Tack and Verloo, 1995). Speciation is defined according to Tack and Verloo (1995) as "the identification and quantification of differently defined species, forms, or phases in which an element occurs". It is widely accepted that to assess the environmental input of soil pollution, the determination of metals speciation will give more information about the potential for release of contaminants and subsequent toxicity. Therefore, in environmental studies of risk assessment, chemical partitioning among the various phases is more useful than the measurement of total heavy metal contents (Albores et al., 2000;Osakwe, 2010;Uba et al., 2008; Odoh et al., 2011). Among the procedures for sequential extraction is that of Tessier et al. (1979). Unlike organic pollutants, heavy metals do not decay and thus pose a different kind of challenge for remediation.

There is no information on speciation of metals in the particulate dust of Funtua textile limited, Katsina State, Nigeria. Despite being one of the leading functional textile industries in northern Nigeria. This work was therefore undertaken to assess the heavy metal load of particulate dust using modified sequential extraction method of Tessier et al.(1979).The metals investigated include $\mathrm{Cd}, \mathrm{Cr}, \mathrm{Cu}, \mathrm{Ni}$, and $\mathrm{Pb}$. These metals were selected because of their toxicity $(\mathrm{Cd}, \mathrm{Cr}, \mathrm{Ni}$, and $\mathrm{Pb})$ and also as an indicator of environmental pollution, Wood (1974) indicated that these metals have known pollutant properties, are toxic and readily available to the environment. Therefore, monitoring of particulate matter especially with heavy metals is imperative.

Based on the above facts, the present study assessed the distribution pattern of some heavy metals $(\mathrm{Cd}, \mathrm{Cr}$, $\mathrm{Cu}, \mathrm{Ni}$, and $\mathrm{Pb}$ ) in industrial particulates dust in Funtua textile limited using modified sequential extraction method by Finzgar et al. (2007).

\section{MATERIALS AND METHODS}

\section{Study Area}

Funtua is located at latitude $11^{\circ} 32^{\prime} \mathrm{N}$ and longitude $7^{\circ} 19^{\prime}$ E (Figure 1), it is a Local Government area of Katsina State. It has an area of $448 \mathrm{~km}^{2}$ and a population of 420,110 (National Population census,2012). The mean annual rainfall in the area is $1024 \mathrm{~mm}$. Annual temperature varies between $21.9-29.2^{\circ} \mathrm{C}$ (Africa Atlas, 2002). The selected area for this investigation was Funtua Textile Industry. It was established to make effective use of the cotton which is grown in large quantity at Funtua town and environs. The industry is active 24 hours a day, six days a week. The sampling points were selected from each department and two random points within the vicinity: Ginning Department $(\mathrm{G})$, Spinning Department: Blowing \& Carding $\left(\mathrm{S}_{1}\right)$, Combing, Spinning \& roving $\left(\mathrm{S}_{2}\right)$. 
Weaving Department: Doubling \& Bleaching $\left(\mathrm{W}_{1}\right)$, Weaving knitting $\left(W_{2}\right)$, Dyeing Department: Dyeing \& finishing (D), Engineering Department: Maintenance $\left(E_{1}\right)$, Power House $\left(E_{2}\right)$, Ginning surrounding (Outside $\mathrm{O}_{1}$ ), Dyeing surrounding (Outside $\mathrm{O}_{2}$ ), with a Control area (C) at Dikke Village about $2 \mathrm{~km}$ away from the study area.

\section{Sample Collection and Pre-treatment}

Twenty-two (22) samples of particulates dust were collected across the sampling points using a plastic brush and tray (Loredo et al., 2003; Yeung et al., 2003) and stored in clean polythene bags (Al-Kashman, 2004), thereafter, labelled accordingly. The homogenized particulate dust samples were air dried and sieved through a $75 \mu \mathrm{m}$ stainless steel sieve to remove extraneous matter such as pieces of brick, paving stone and other debris. Care was taken to reduce the disturbance of the fine particles, which could be readily lost by re-suspension (Manta et al., 2002).Range of temperature across the sites was $28.39^{\circ} \mathrm{C}\left(\mathrm{W}_{2}\right)$ $32.07^{\circ} \mathrm{C}(\mathrm{C})$ and $29.50^{\circ} \mathrm{C}\left(\mathrm{W}_{2}\right)-32.43^{\circ} \mathrm{C}\left(\mathrm{O}_{1}\right)$ for morning and evening periods respectively.

\section{Quality Assurance}

All reagents used were of analytical grade, distilled deionized water was used. All the glass wares and polythene sample bottles were washed with liquid soap, rinsed with distilled water, soaked in $10 \% \mathrm{HNO}_{3}$ for 24 hours and rinsed thoroughly with distilled de-ionized water and thereafter dried (Todorovi et al., 2001). Validation of the technique was conducted on the digested dust sample. This was done by spiking the predigested sample with multi-element standard solution ( 5 $\mathrm{mg} / \mathrm{dm}^{3}$ of $\mathrm{Cd}, \mathrm{Cu}, \mathrm{Ni}, \mathrm{Pb}$ and $0.5 \mathrm{mg} / \mathrm{dm}^{3} \mathrm{Cr}$ ) as reported by Awofolu, (2005).

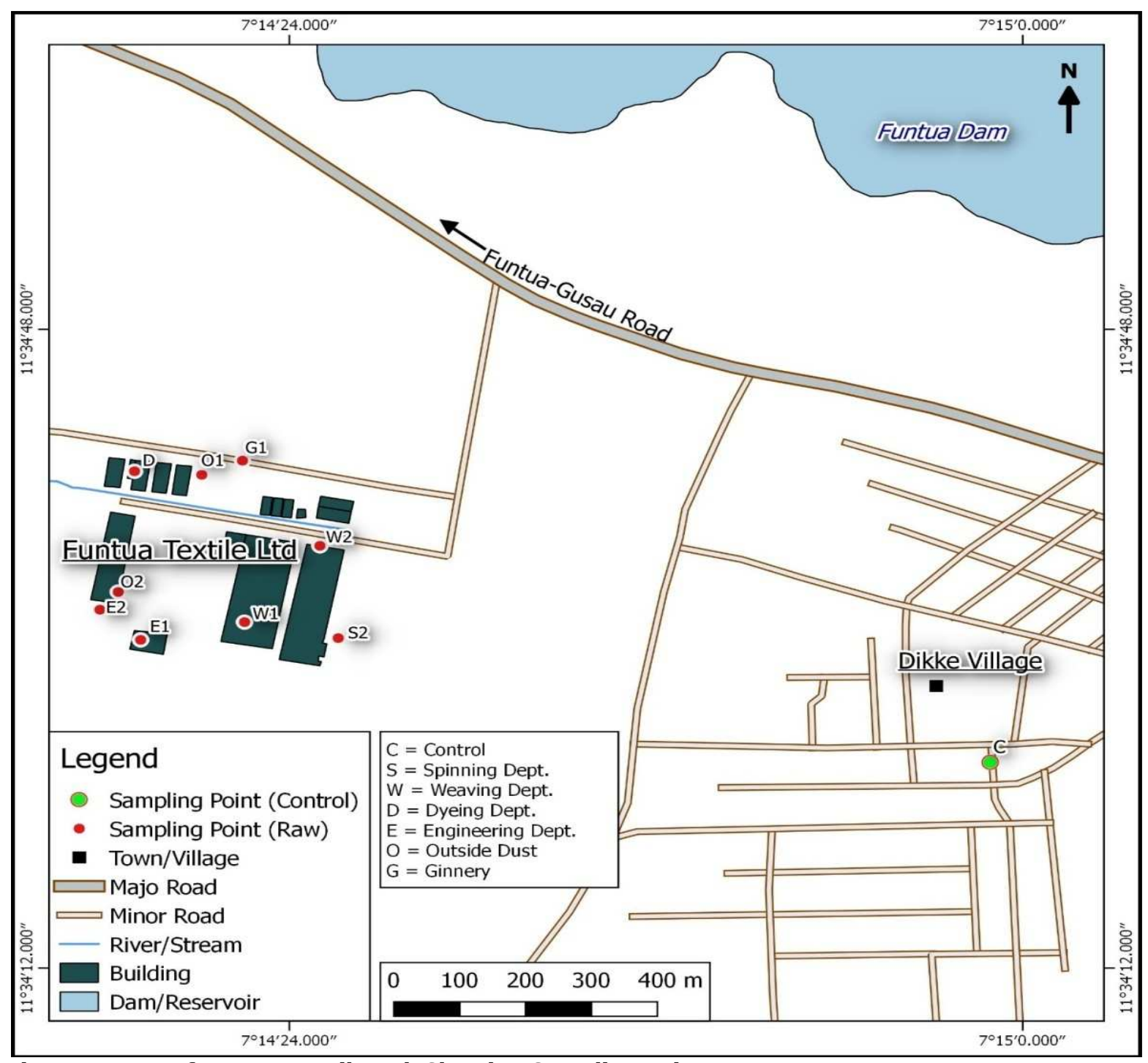

Figure 1: Map of Funtua Textile Ltd. Showing Sampling Point Source: Modified from the Administrative Map of Funtua L.G.A. 


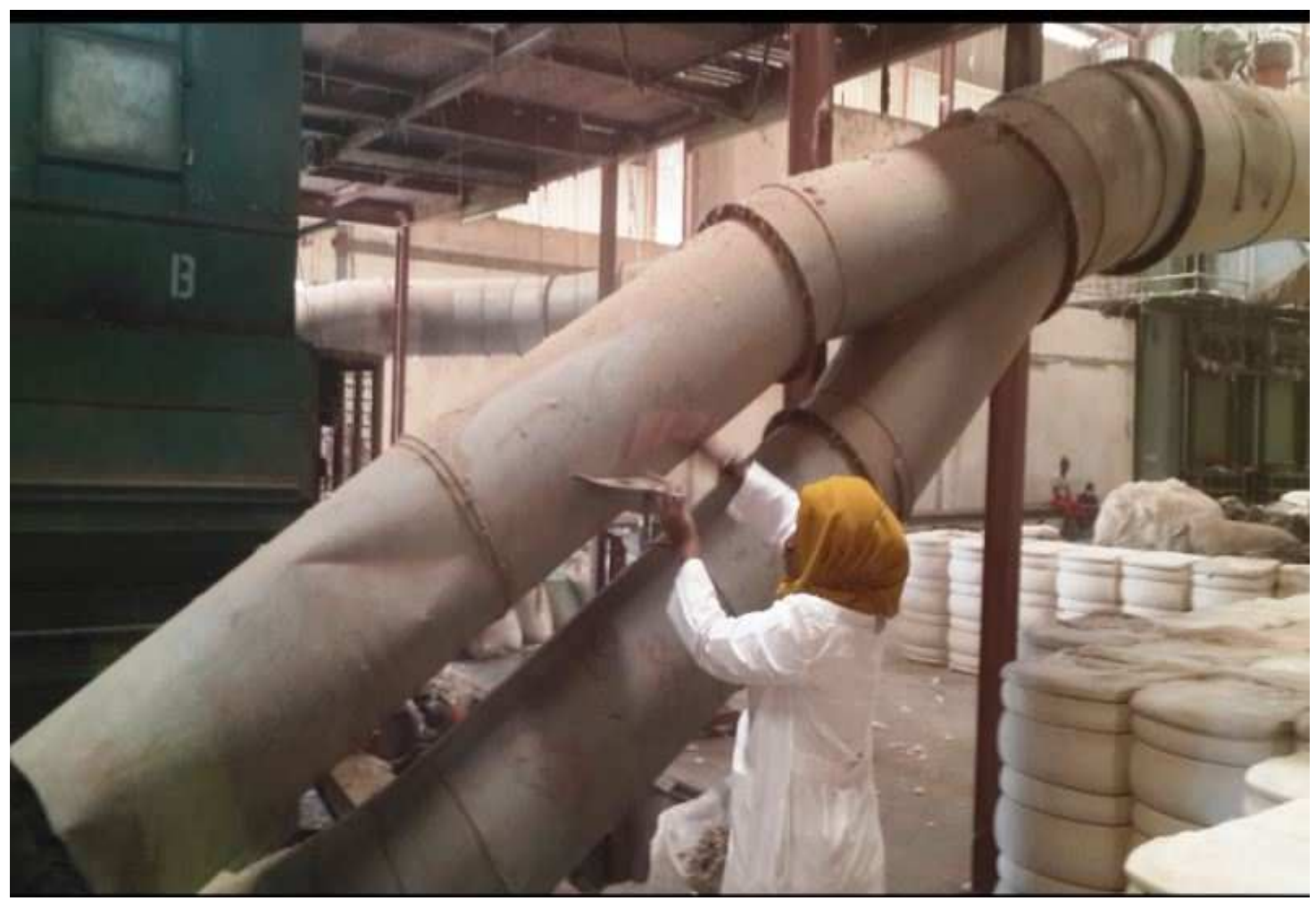

Plate I: Particulates dust sampling at Ginning Department (G)

Metal Extraction of Industrial Particulates Dust

Sequential extraction was done using Finžgar et al. (2007) method. The method was modified by Tessier et al. (1979). This modified method fractionates heavy metals into six geochemical fractions. The extraction was carried out with initial mass of $1.0 \mathrm{~g}$ air-dried dust samples in polypropylene centrifuge tubes of $50 \mathrm{~cm}^{3}$ capacity. However, $\mathrm{Mg}\left(\mathrm{NO}_{3}\right)_{2}$ was used instead of $\mathrm{MgCl}_{2}$ to avoid an increase in the solubility of heavy metals within the particulates dust in the solution matrix (Shuman, 1985). The extractions of the dust samples were carried out on three sub-samples as follows:

Fraction I (Water soluble phase): One gram $(1 \mathrm{~g})$ of the air-dried dust sample (sieved) was mixed with 10 $\mathrm{cm}^{3}$ of de-ionized water with continuous agitation for 1 hour. The mixture was centrifuged and the supernatant decanted and made up to $50 \mathrm{~cm}^{3}$ with de-ionized water prior to analysis.

Fraction II (Exchangeable phase): The residue from step 1 was shaken at room temperature with 16 $\mathrm{cm}^{3}$ of $1 \mathrm{M} \mathrm{Mg}\left(\mathrm{NO}_{3}\right)_{2}$ at $\mathrm{pH} 7.0$ for 1 hour.The mixture was then centrifuged and supernatant filtered and made up to $50 \mathrm{~cm}^{3}$ with distilled de-ionized water.

Fraction III (Oxidisible phase bound to Organic matter): Residue from $2+10 \mathrm{~cm}^{3} \mathrm{H}_{2} \mathrm{O}_{2} 8.8 \mathrm{M}+6 \mathrm{~cm}^{3}$ $\mathrm{HNO}_{3} 0.02 \mathrm{M}$ was shaken for 5 hours +1 hour at $98{ }^{\circ} \mathrm{C}$. $10 \mathrm{~cm}^{3}$ of $3.5 \mathrm{M} \mathrm{CH}_{3} \mathrm{COONH}_{4}$ was added as an extracting agent, then the mixture was centrifuged and supernatant filtered and made up to $50 \mathrm{~cm}^{3}$ with distilled water prior to analysis.

Fraction IV (Acid soluble fraction bound to carbonate):A volume of $25 \mathrm{~cm}^{3}, 0.05 \mathrm{M} \mathrm{Na}_{2}$ EDTA was added to the residue from 3 , shaken for 6 hours and the mixture was centrifuged and the supernatant filtered and made up to $50 \mathrm{~cm}^{3}$ with distilled water prior to analysis.

Fraction $\mathbf{V}$ (Reducible phase bound to Fe-Mn oxides): Residue from $4+17.5 \mathrm{~cm}^{3}$ of $0.1 \mathrm{M}$ $\mathrm{NH}_{2} \mathrm{OH} . \mathrm{HCl}+17.5 \mathrm{~cm}^{3}$ of $3.5 \mathrm{M} \mathrm{CH}_{3} \mathrm{COONH}_{4}$ was shaken for 1 hour, the mixture was then centrifuged. The supernatant was filtered and made up to $50 \mathrm{~cm}^{3}$ with distilled water prior to analysis.

Fraction VI (Residual phase bound to silicates and detrital materials): Residue from 5 was digested by using $\mathrm{HCl}-\mathrm{HNO}_{3} / \mathrm{HF}(0.35: 12 \mathrm{w} / \mathrm{v}$ soil solution ratios) in acid digestion in a Teflon cup. It was then ash-dried for 2 hours and evaporated to dryness. The residue was diluted to $50 \mathrm{~cm}^{3}$ with distilled de-ionized water prior to analyses.

After each successive extraction, the sample was centrifuged at $3000 \mathrm{rpm}$ for 15 minutes. The supernatant was removed with pipette and filtered with Whatman No. 42 filter paper. The residue in each case washed with distilled de-ionized water followed by vigorous hand shaking and then 15 minutes centrifugation before the next extraction (Shuman, 1985). 


\section{Sample Digestion}

A mass $2.0 \mathrm{~g}$ of the dried sample was accurately weighed into a conical flask and $10 \mathrm{~cm}^{3}$ of nitric acid was added and the mixture was heated on a hot plate until the sample was almost dry and then cooled. The procedure was repeated with another $10 \mathrm{~cm}^{3}$ of concentrated nitric acid followed by the addition of 10 $\mathrm{cm}^{3}$ of $2 \mathrm{M}$ Hydrochloric acid. The digested dust was warmed with $20 \mathrm{~cm}^{3}$ of $2 \mathrm{M} \mathrm{HCl}$ and filtered into a 50 $\mathrm{cm}^{3}$ volumetric flask through Whatman filters (No. 1), thereafter, diluted to the mark with double distilled water (Divrikli et al., 2003). The metals in the final solutions were determined by Atomic Absorption Spectrophotometer (Varian AA650FS).

\section{RESULTS AND DISCUSSION}

Among the six geochemical fractions, the highest concentrations of $\mathrm{Cd}$ were recorded in the non-residual fractions of $E_{2}$, as presented in Figures: $2-12$ which shows that they would be released into the environment easily. Also, the percentages of the bioavailable fractions of $\mathrm{Cd}$ were significantly high across the sites with the exception of particulate dust of sites $C_{1}, W_{1}$ and $W_{2}$, respectively. This indicates that the $C d$ studied would be readily bioavailable to the environment for contamination in all but sites $C, W_{1}$ and $W_{2}$ respectively. Thus, Cd could be easily transferred into the food chain through the uptake by plants growing in the soils, or through inhalation of the particulate dust. These characteristics, in addition to health hazards of $\mathrm{Cd}$ to human health, suggest that frequent examination of the levels of this element in soil samples could determine potential health hazards to residents and workers living near and within the factory. Overall, the total extractable fractions of $\mathrm{Cd}$ across the sites were above the USEPA, (1998) limit of $3.0 \mathrm{mgkg}^{-1}$ for Cd in soil. The presence of the appreciable percentages of $\mathrm{Cd}$ in the mobile phase suggests that $\mathrm{Cd}$ in these dust particulates was potentially highly bioavailable for plant uptake (Uba et al., 2008; Xian, 1989). The results obtained in this study were in agreement with those reported by Harrison, (1981); Kuo et al. (1983); Miller and Mcfee, (1983) anUba et al.(2008).

Furthermore, the highest concentrations of $\mathrm{Cr}$ across the sites were recorded in the residual fractions, with site $\mathrm{W}_{2}(100 \%)$ having the highest value and site $\mathrm{W}_{1}$ $(73.46 \%)$ having the lowest value. According to Venkateswaran et al. (2007). The leaching of $\mathrm{Cr}$ to the environment may not easily occur. $\mathrm{Cr}$ (VI) is a highly toxic metal that has been linked to cancer in human following prolonged inhalation (USEPA, 1998). Similarly, the percentage bioavailable and non-residual fractions of $\mathrm{Cr}$ were significantly low across the sites which suggests that $\mathrm{Cr}$ is not easily released into the environment and hence to plants. Most of the values of $\mathrm{Cr}$ obtained in the residual and non-residual fractions were above the critical level of $0.03 \mathrm{mgkg}_{1}^{-1}$ for soils recommended by FEPA, (1991). Furthermore, the $\mathrm{Cr}$ content of the soil fractions was strongly associated with the residual fractions which are in agreement with those reported in similar studies by Uba et al. (2008). The concentrations of $\mathrm{Cu}$ in the extractable fractions as determined by sequential extractions across the sites shows the highest concentrations of $\mathrm{Cu}$ were recorded in the non-residual fractions, although appreciable percentages were also recorded in the residual fractions.

The high amount of $\mathrm{Cu}$ being associated with the nonresidual fraction across sites show that Cu may be easily transferred into the food chain through water reservoir, uptake by plants growing on the factory soil which could have potential negative impact on the environment and consequently on human health. The total extractable concentrations of $\mathrm{Cu}$ in all the dust particulates samples (Table: 1) were below the toxic limit of $140 \mathrm{mgkg}^{-1}$ set by EC, (2005) and also below $100 \mathrm{mgkg}^{-1}$ toxic limits set by USEPA, 1998. On comparing the concentrations of $\mathrm{Cu}$ in the residual and non-residual fraction, the higher percentage of the non-residual fraction was generally found in dusts of site $E_{1}$. The bioavailability of Cu across the sites was generally high; this clearly shows that the metal would be released into the environment easily as it is known to be associated with organic humus so it need not be subjected to harsh conditions. The relatively high value of $\mathrm{Cu}$ in the residual fraction () indicates that it's largely embedded in the crystal lattice of the soil fraction and should not be available for environmental pollution except under harsh conditions.

The concentrations of $\mathrm{Cu}$ obtained in this study were similar to those reported by Uba et al., (2008). Moreso, the highest value of the extractable fractions of $\mathrm{Ni}$ was found in the residual fraction. Also, relatively high values of $\mathrm{Ni}$ were found in the non-residual fractions which suggest possible contamination of plant around the vicinity of the factory by Ni.On the other hand the high value of $\mathrm{Ni}$ in the residual fraction shows that they would be released into the environment under very harsh conditions by sequential extraction procedure. The values of $\mathrm{Ni}$ in the dust particulates were above the FEPA, 1991 (maximum permissible limits of $3.0 \mathrm{mgkg}^{-1}$ ). The non-residual fraction has the highest potential of contamination of food chain, surface water and ground water (Leita et al., 1991). The relatively high percentage bioavailability of $\mathrm{Ni}$ suggest that it could be readily available to the environment for contamination causing environmental toxicity during mobility especially at site $E_{2}$ which is engineering unit with a lot of wastes like spent engine oil, used generator batteries and oil mist. The extractable fractions of $\mathrm{Pb}$ in the studied areas among the extractable fraction of $\mathrm{Pb}$, the highest concentration of $\mathrm{Pb}$ were recorded in the non-residual fraction (Figures: $2-12$ ). On comparing the levels of $\mathrm{Pb}$ recorded in the residual and non-residual fraction, the former constitutes also relatively high percentage of the total extractable fraction as compared with the latter, which suggests that $\mathrm{Pb}$ at these sites would need to be subjected to harsh conditions before they can be bioavailable to the plants. Also, the levels of $\mathrm{Pb}$ recorded among the fractions were below the USEPA, (1998) toxic limits of $100 \mathrm{mgkg}^{-1}$ in soil. 
The findings in this study were in agreement with what was reported by KabataPendias and Pendias (1992) who stated that there was a strong association of $\mathrm{Pb}$ with organic matter. In general, the oxide (organic bound) fractions scavenge $\mathrm{Pb}$ in natural and polluted soils (Kuo et al., 1983; Xian, 1989) indicating the tendency of $\mathrm{Pb}$ to be released into the environment. The percentage bioavailable $\mathrm{Pb}$ was quite low compared to other metals and fractions. $\mathrm{Pb}$ is notorious for its lack of soil mobility, primarily due to its precipitation as insoluble phosphate, carbonate, and hydroxide which have low solubility in water (Rieuwerts et al., 2006). Low levels of bioavailable $\mathrm{Pb}$ or low mobility found in soils (dust) has been attributed to one or combination of low native $\mathrm{Pb}$, very slow solubilisation of $\mathrm{Pb}$ from soil minerals, strong adsorption of $\mathrm{Pb}$ on soils surface or co-leaching of $\mathrm{Pb}$ with dissolved organic matter (Rieuwerts et al., 2006). The values obtained in this study were similar to those reported by Uba et al.(2008). Heavy metal speciation studies are important since slight changes in metal availability and in environmenta conditions can lead to serious health problems such as respiratory, cardiovascular and other diseases.

\begin{tabular}{|c|c|c|c|c|c|c|}
\hline SITES & FRACTIONS (\%) & Cd (\%) & $\operatorname{Cr}(\%)$ & Cu (\%) & $\mathrm{Ni}(\%)$ & Pb (\%) \\
\hline \multirow{3}{*}{ G } & Bioavailable & 56.45 & 0.00 & 41.01 & 32.34 & 30.39 \\
\hline & Non-residual & 59.68 & 10.17 & 42.76 & 32.34 & 48.21 \\
\hline & Residual & 40.32 & 89.83 & 57.24 & 67.66 & 51.79 \\
\hline \multirow{3}{*}{$\mathrm{S}_{1}$} & Bioavailable & 67.39 & 0.00 & 35.85 & 22.74 & 38.80 \\
\hline & Non-residual & 77.17 & 1.02 & 37.71 & 22.74 & 75.42 \\
\hline & Residual & 22.83 & 98.98 & 62.29 & 77.26 & 24.58 \\
\hline \multirow{3}{*}{$\mathrm{S}_{2}$} & Bioavailable & 66.67 & 0.00 & 24.41 & 27.62 & 22.09 \\
\hline & Non-residual & 85.19 & 0.44 & 32.19 & 27.62 & 38.32 \\
\hline & Residual & 14.81 & 99.56 & 67.81 & 72.38 & 61.68 \\
\hline \multirow{3}{*}{$\mathrm{W}_{1}$} & Bioavailable & 30.36 & 3.00 & 34.98 & 30.94 & 33.57 \\
\hline & Non-residual & 44.64 & 26.54 & 64.68 & 32.79 & 57.35 \\
\hline & Residual & 55.36 & 73.46 & 35.32 & 67.21 & 42.65 \\
\hline \multirow{3}{*}{$\mathrm{W}_{2}$} & Bioavailable & 34.44 & 0.00 & 22.16 & 28.91 & 25.15 \\
\hline & Non-residual & 42.22 & 0.00 & 28.96 & 28.91 & 42.29 \\
\hline & Residual & 57.78 & 100.00 & 71.04 & 71.09 & 57.71 \\
\hline \multirow{3}{*}{$\mathrm{D}$} & Bioavailable & 74.29 & 8.47 & 51.63 & 66.46 & 41.56 \\
\hline & Non-residual & 91.43 & 11.48 & 74.48 & 66.46 & 78.29 \\
\hline & Residual & 8.57 & 88.52 & 25.52 & 33.54 & 21.71 \\
\hline \multirow{3}{*}{$\mathrm{E}_{1}$} & Bioavailable & 83.64 & 0.00 & 0.09 & 38.43 & 23.44 \\
\hline & Non-residual & 92.73 & 6.27 & 92.73 & 60.33 & 74.07 \\
\hline & Residual & 7.27 & 93.73 & 7.27 & 39.67 & 25.94 \\
\hline \multirow{3}{*}{$\mathrm{E}_{2}$} & Bioavailable & 64.44 & 21.19 & 53.40 & 69.56 & 38.94 \\
\hline & Non-residual & 97.78 & 23.88 & 67.02 & 76.36 & 75.34 \\
\hline & Residual & 2.22 & 76.12 & 32.98 & 23.64 & 24.66 \\
\hline \multirow{3}{*}{$\mathrm{O}_{1}$} & Bioavailable & 49.15 & 0.00 & 25.87 & 35.31 & 24.06 \\
\hline & Non-residual & 66.10 & 10.24 & 25.87 & 35.31 & 47.62 \\
\hline & Residual & 33.90 & 89.76 & 74.13 & 64.69 & 52.38 \\
\hline \multirow{3}{*}{$\mathrm{O}_{2}$} & Bioavailable & 39.68 & 2.04 & 56.93 & 36.04 & 24.42 \\
\hline & Non-residual & 57.14 & 2.04 & 60.15 & 36.04 & 46.44 \\
\hline & Residual & 42.86 & 97.96 & 39.85 & 63.96 & 53.56 \\
\hline \multirow{3}{*}{$\mathrm{C}$} & Bioavailable & 21.15 & 4.17 & 27.98 & 24.66 & 27.26 \\
\hline & Non-residual & 44.23 & 4.17 & 27.98 & 24.66 & 50.36 \\
\hline & Residual & 55.77 & 95.83 & 72.02 & 75.34 & 49.64 \\
\hline
\end{tabular}

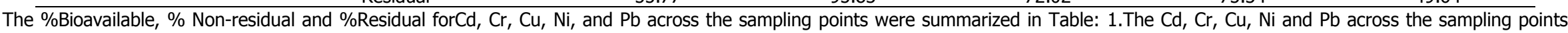
were summarised in Figures: $2-12$. 
Bajopas Volume 10 Number 2 December, 2017

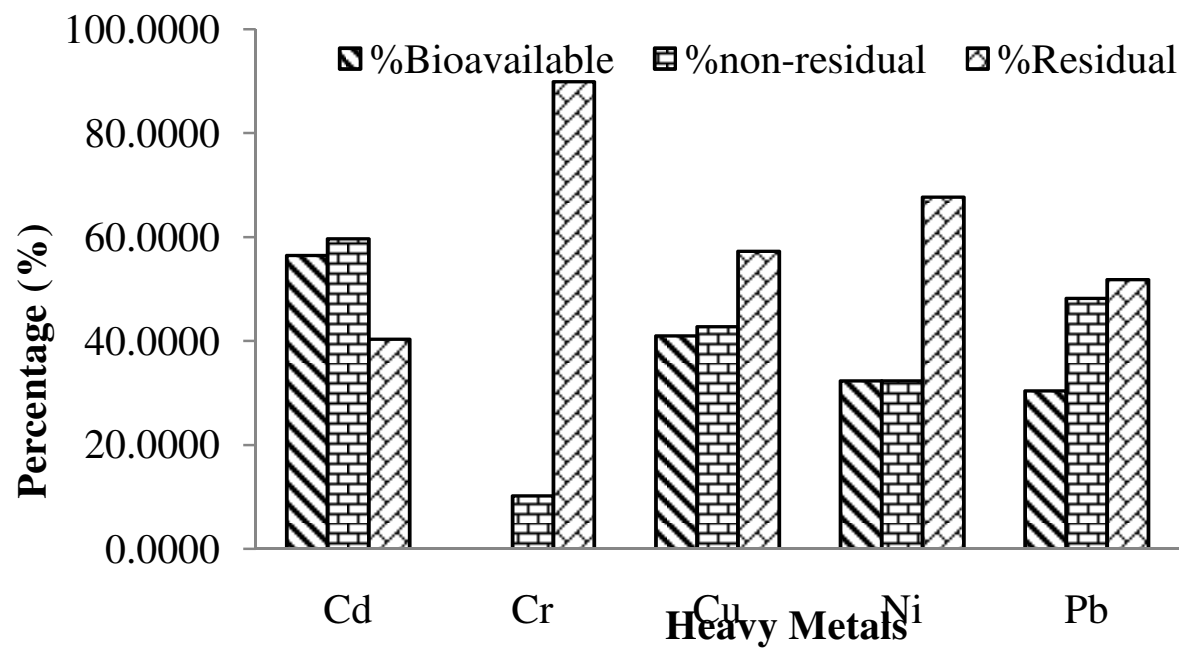

Figure 2: Percentage bioavailable, non-residual and residual fractions in dust particulates at G (Ginnery section) of Funtua Textile LTD

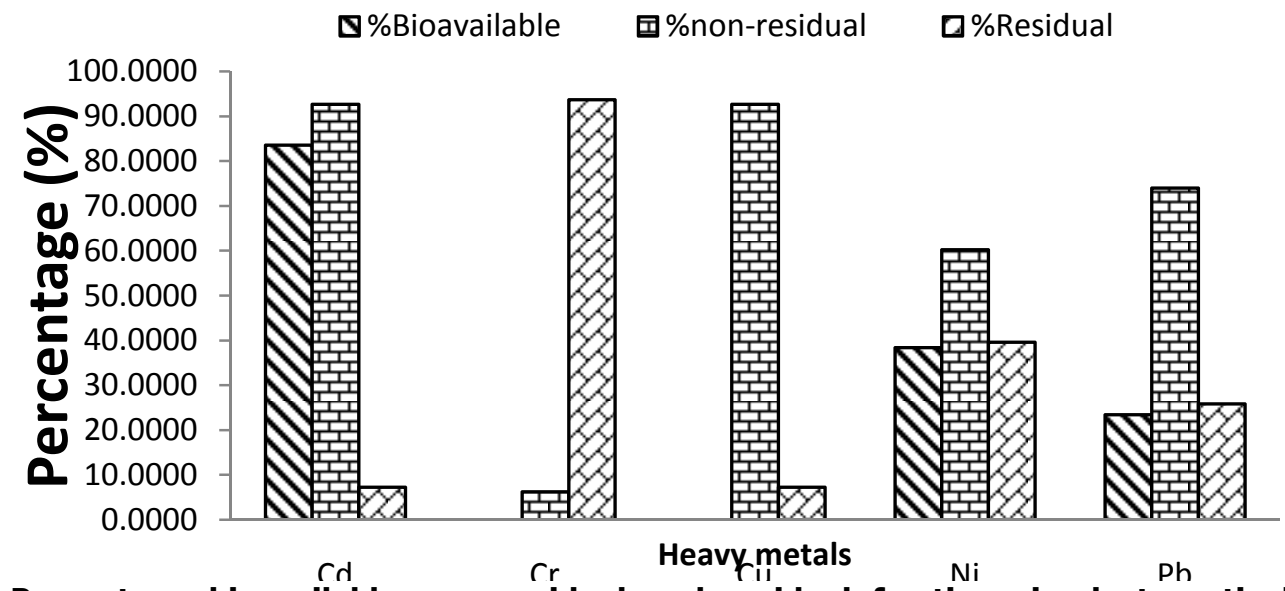

Figure 3: Percentage bioavailable, non-residual and residual fractions in dust particulates at $E_{1}$ (engineering section) of Funtua Textile LTD

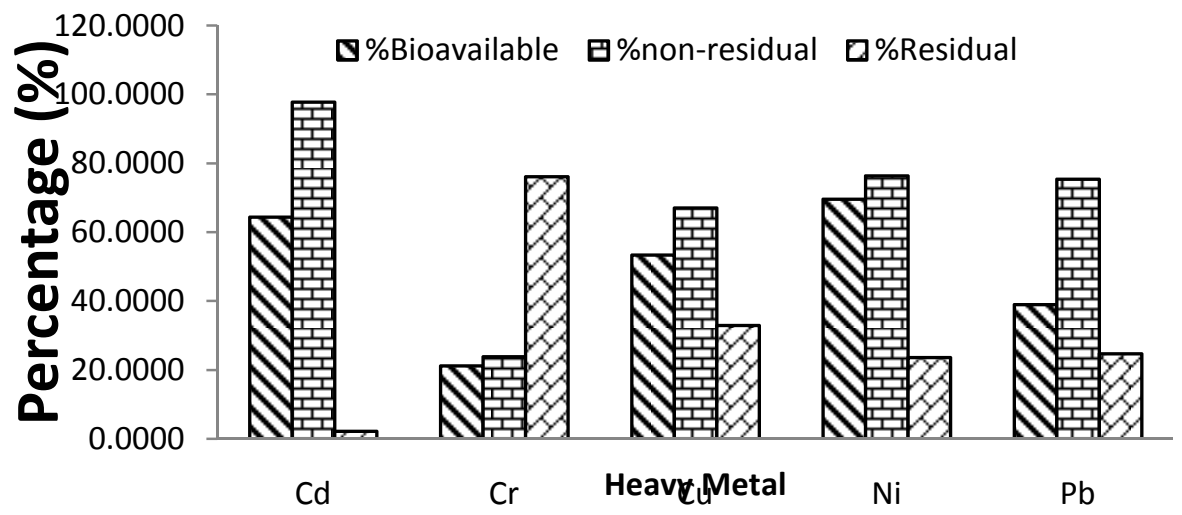

Figure 4: Percentage bioavailable, non-residual and residual fractions in dust particulates at $E_{2}$ (power house section) of Funtua Textile LTD 
Bajopas Volume 10 Number 2 December, 2017

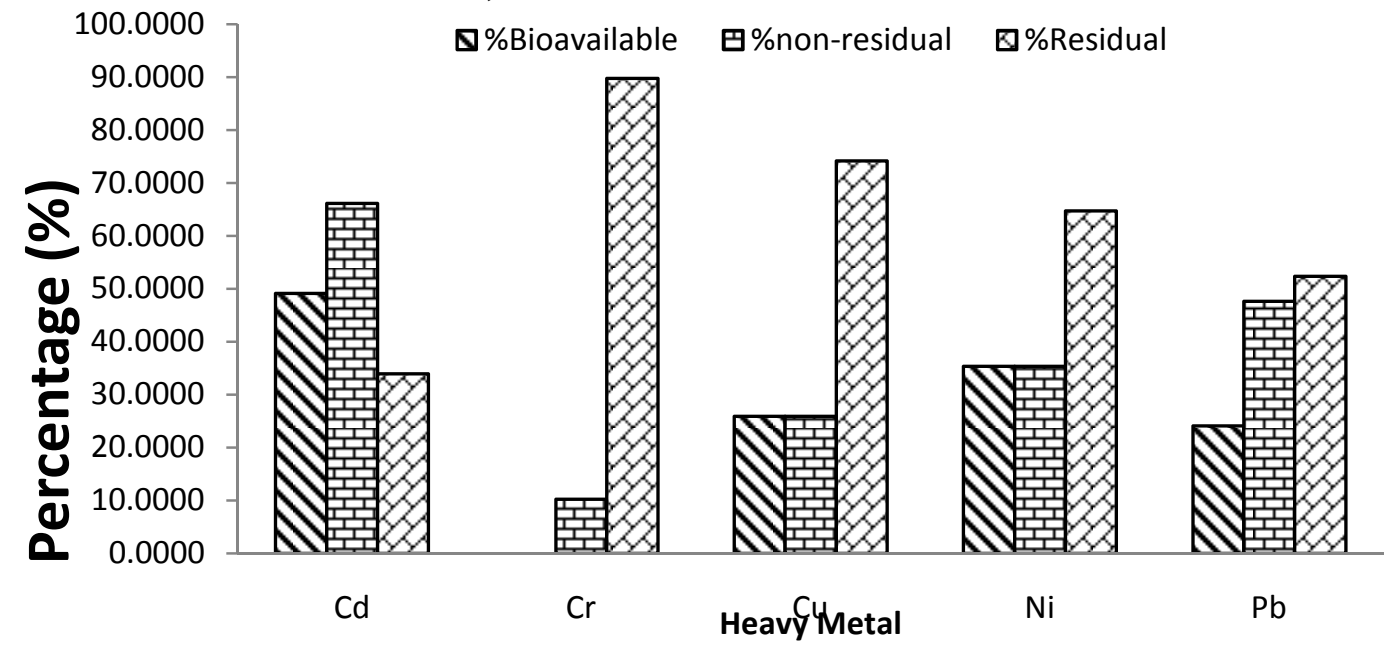

Figure 5: Percentage bioavailable, non-residual and residual fractions in dust particulates at $\mathbf{O}_{1}$ (ginning surrounding section) of Funtua Textile LTD

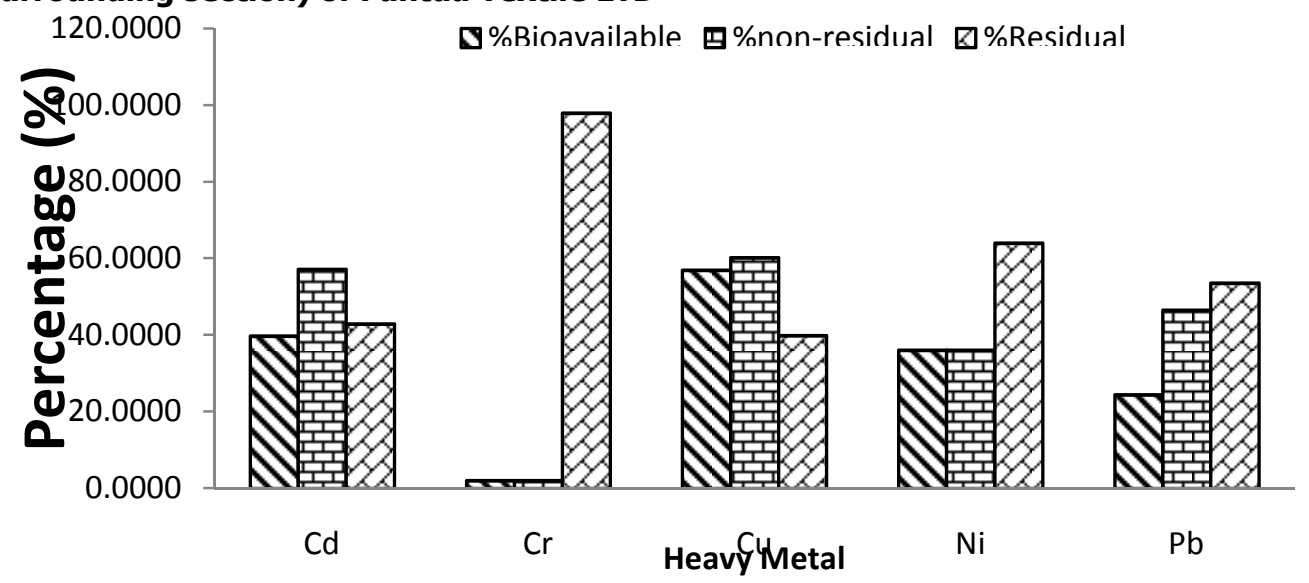

Figure 6: Percentage bioavailable, non-residual and residual fractions in dust particulates at $\mathbf{O}_{2}$ (dyeing surrounding section) of Funtua Textile LTD

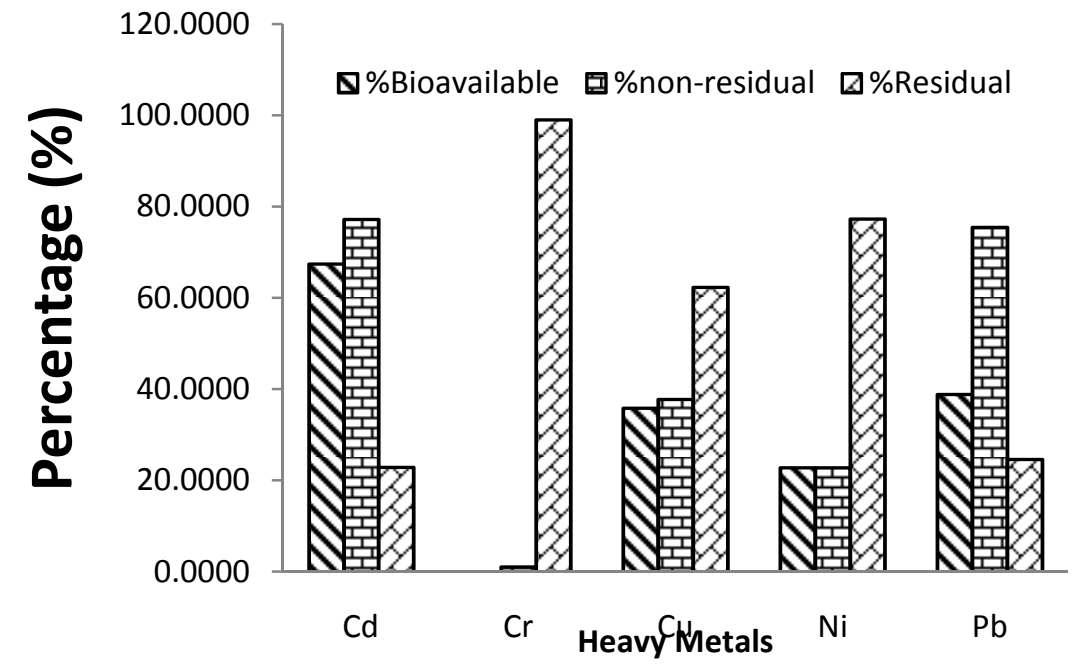

Figure 7: Percentage bioavailable, non-residual and residual fractions in dust particulates at $S_{1}$ (blowing and carding section) of Funtua Textile 
Bajopas Volume 10 Number 2 December, 2017

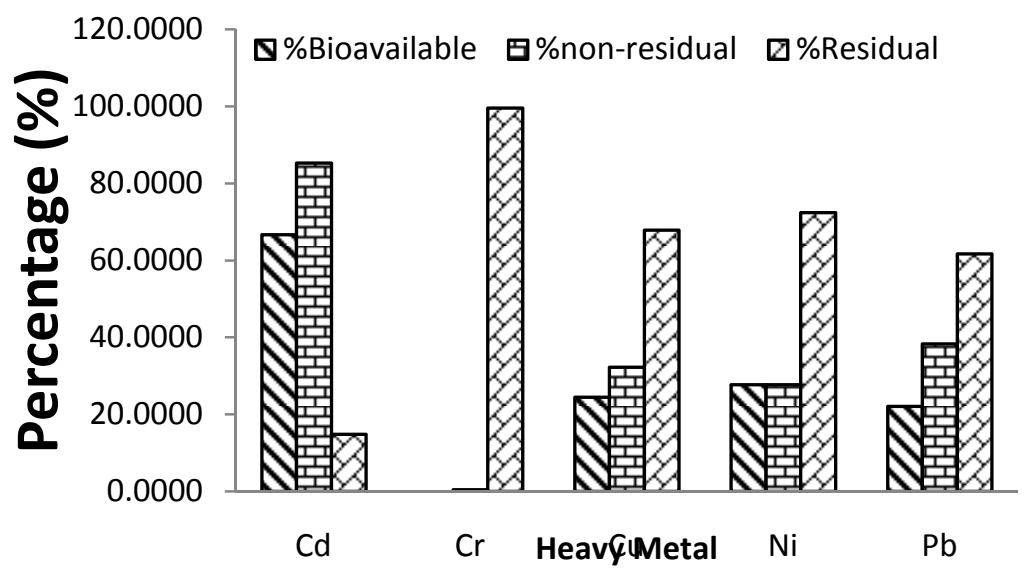

Figure 8: Percentage bioavailable, non-residual and residual fractions in dust particulates at $S_{2}$ (spinning and roving section) of Funtua Textile LTD

$\boldsymbol{\nabla} \%$ Bioavailable $\mathbf{\nabla} \%$ non-residual $\square \%$ Residual

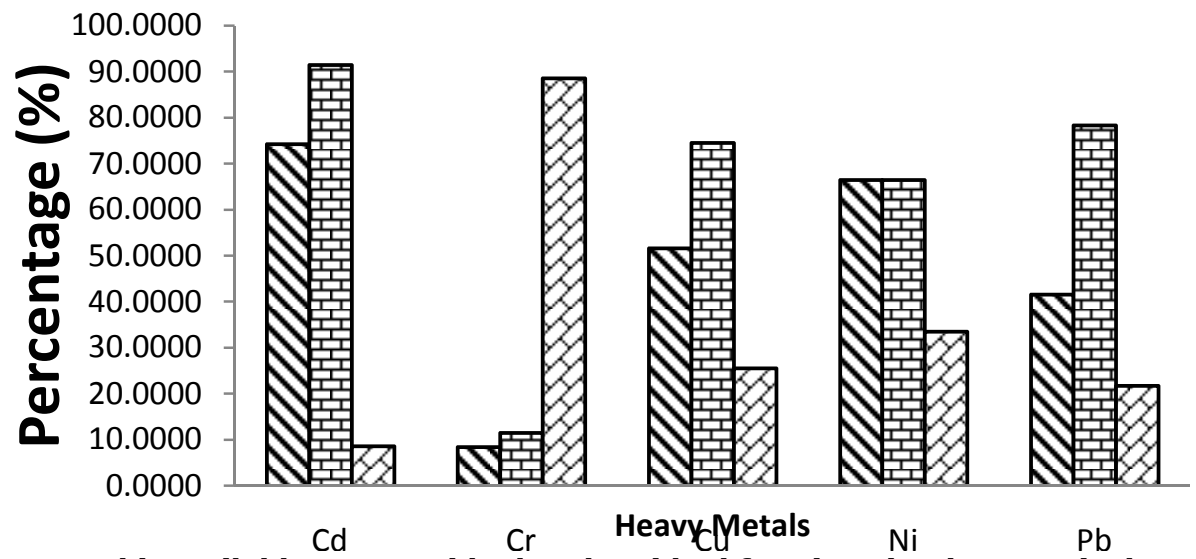

Figure 9: Percentage bioavailable, non-residual and residual fractions in dust particulates at $D$ (dyeing section) of Funtua Textile LTD

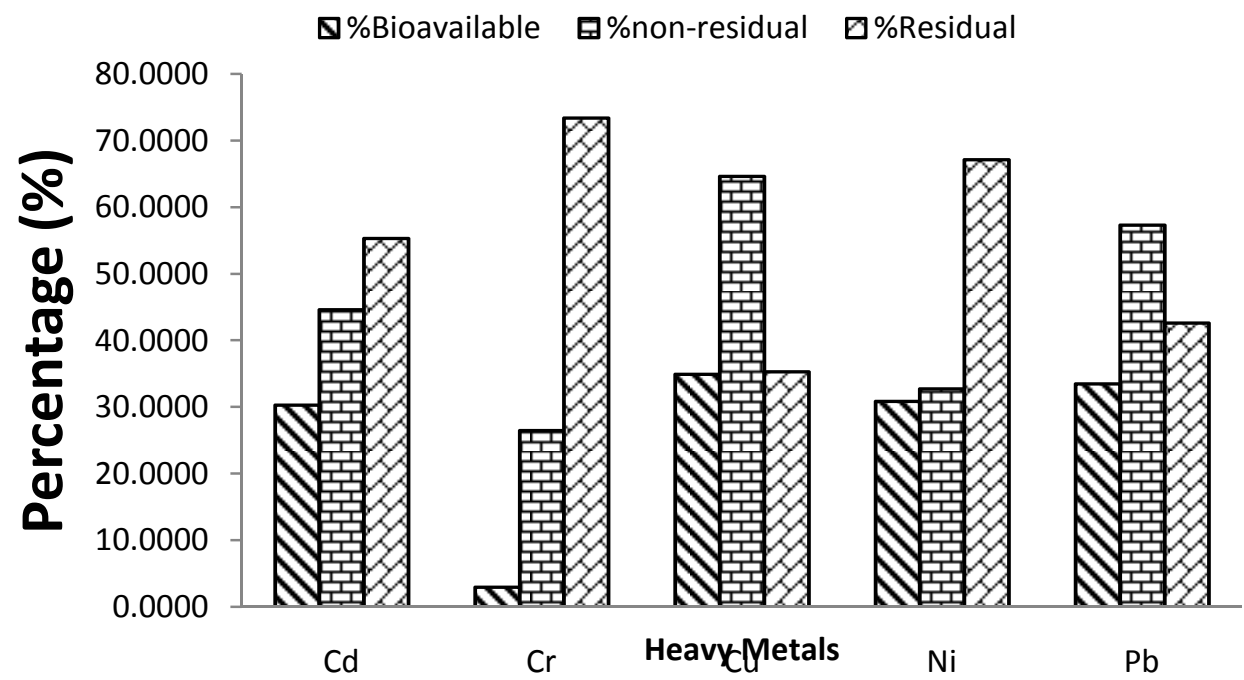

Figure 10: Percentage bioavailable, non-residual and residual fractions in dust particulates at $W_{1}$ (doubling and bleaching section) of Funtua Textile LTD 

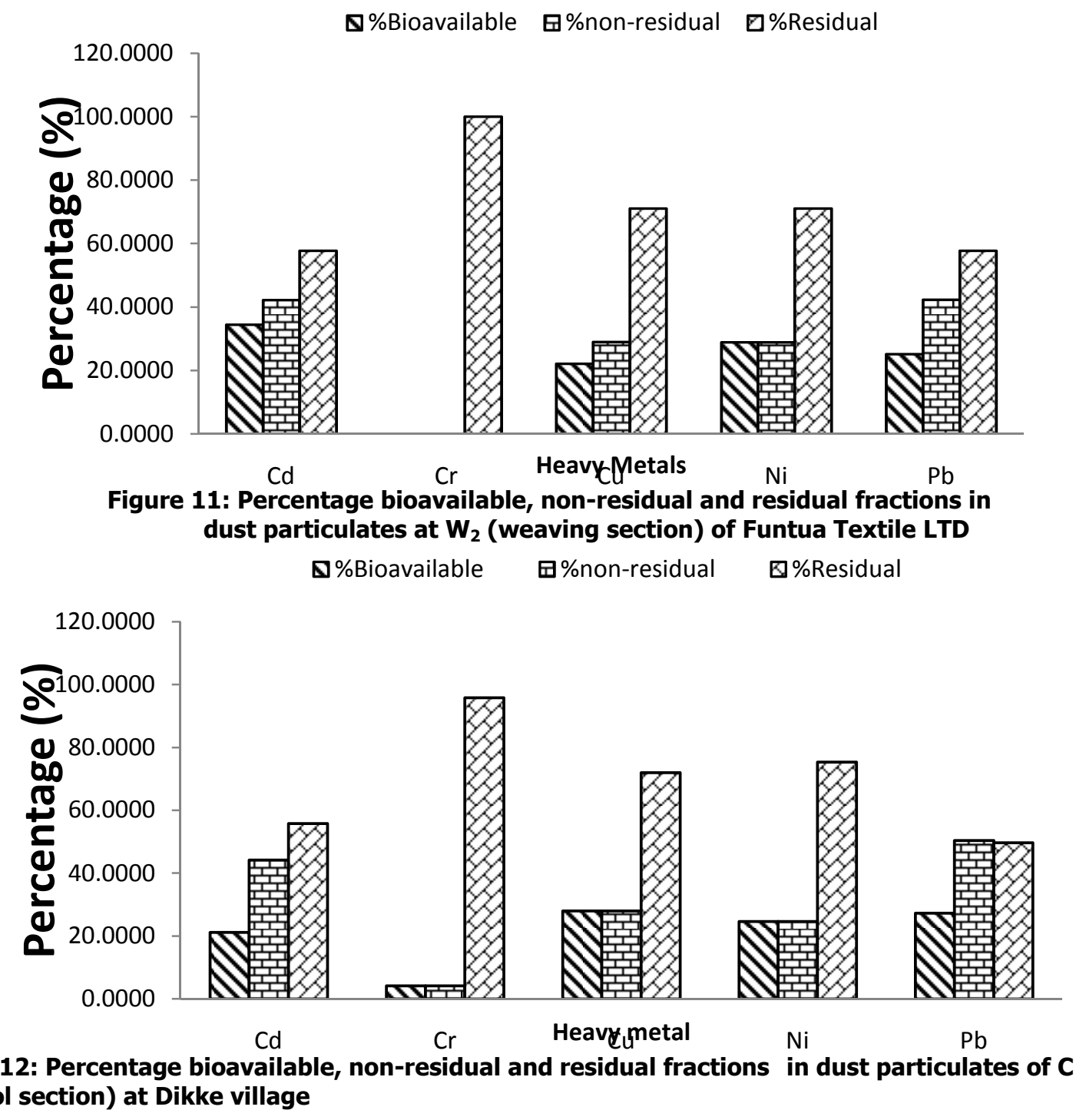
(control section) at Dikke village

\section{CONCLUSION}

The industrial dust collected from Funtua textile limited shows high concentrations of heavy metals ( $\mathrm{Cd}$ and $\mathrm{Cu}$ )which could lead to serious environmental hazards. The sequential extractions procedure showed significant amount of $\mathrm{Cu}$ were associated with non-residual and organic bound fractions. Similarly, $\mathrm{Cd}$ is also associated with the non-residual fractions across the sampling sites. For $\mathrm{Cr}$ and $\mathrm{Ni}$, their occlusion in crystal lattice (residual fraction) of the soil fractions exhibited the highest percentage. Lead $(\mathrm{Pb})$ in the particulate dust samples was found to be significantly associated with the non-residual fraction and carbonate bound fraction with a range of $21.71(\mathrm{D})-61.68\left(\mathrm{~S}_{2}\right) \%$ across the sites. This study indicated that industrial particulate dust pollution due to metals such as $\mathrm{Cu}, \mathrm{Cr}$ and $\mathrm{Pb}$ may pose serious health risks to the residents in this rapidly developing industry.

\section{Recommendation}

It is therefore recommended that for a safer environment, proper textile management programmes, proper legislative frame work to regulate pollution and finally proper implementation of these measures be encouraged

\section{Conflict Of Interest}

Authors have declared that no conflicting interest exist

\section{Acknowledgments}

The authors wish to acknowledge the entire staff of Multi - user Student Research Laboratory (MUSRL) for carrying out the analysis within a short period of time. Also the entire staff of the Chemistry Department, Ahmadu Bello University are also acknowledged for their immeasurable support in ensuring that the project becomes a success.

\section{Contribution of authors:}

Author S. Uba read and corrected the manuscript performed the statistical analysis. Author S. Abdulkadir designed the study, managed the literature searches and wrote the first draft of the manuscript and Author Y.A Dalltu approved the design and supervised the experiment 


\section{REFERENCES}

Africa atlast, (2002). The WIKIMEDIA COMMONS Atlas of the World is an organized and commented collection of geographical, political and historical maps available at Wikimedia Commons.

Albores, A. F., Perez-Cid, B., Cromes, E. F., Lopez, E. F. (2000). Comparison between Sequential Extraction Procedures and Single Extraction Procedure for Metal Partioning in Sewage Sludge Samples. Analyst. 125; 1353-1357.

Al-Khashman, O.A. (2004). Heavy metals Distribution in Dust, Street Dust and Soil from the workplace in Karak Industrial Estate, Jordan. Atmospheric Environment, 38(39):6803-6812.

Awofolu O.R. (2005). A Survey of Trace Metals in Vegetation, Soil and Lower Animals along Some Selected Major Roads on Metropolitan City of Lagos. Environmental Monitoring and Assessment, 105: 413- 447.

Banat, K. M., Howari,F. M., and Al-HamadA. A., (2005). "Heavy metals in urban soils of central Jordan: should we worry about their environmental risks?" Environmental Research, 97(3): 258273.

Divrikli, U., Soylak, M., Elci, L., andDogan, M. (2003). Trace heavy metal levels in street dust samples from Yozgat City Center, Turkey. Journal of trace and microprobe techniques, 21(2), 351-361.

EC (European Commission), (2005). Commission Regulation (EC) No 78/2005 of 19 January 2005 amending Regulation (EC) No 466/2001 as regards heavy metals, L 16/43-45.

FEPA (1991). Federal Environmental Protection Agency. National Interim Guidelines and Standards for Environmental Pollution Control in Nigeria. Federal Ministry of Environment.

Finžgar, N.P. and Thistos L.D. (2007). Relationship of soil properties to fractionation bioavailability and mobility of lead and zinc in soil. Plant, Soil, Environment, 53(5), 225-238.

Harrison, R.M. (1981). Chemical association of lead, cadmium, copper and zinc, in street Dusts and Roadside Soils. Environmental Science Technology, 15, 1378-1383.

Kabata-Pendias, A. and Pendias, H. (1992). Trace Elements in Soils and Plants. $2^{\text {nd }}$ ed. Lewis Boca Raton, Florida.326-341.

Kuo, S., Heilman, P. E. and Baker, A. S. (1983). Distribution and forms of $\mathrm{Cu}, \mathrm{Zn}, \mathrm{Cd}, \mathrm{Fe}$ and, $\mathrm{Mn}$ in Soil near a Copper Smelter. Soil Science, 135, 10-109.

Leita, L., De Nobili, M., Muhlbachova, G., Mondini, C., Marchiol, L., and Zerbi, G. (1991). Bioavailability and effects of heavy metals on soil microbial biomass survival during laboratory incubation. Biology and Fertility of Soils, 19(2-3), 103-108.

Loredo, J., Ordonez, S., Charlesworth, and De-Mignel, K. (2003). Influence of Industry on the Geochemical Urban Environment of Mieres (Spain) and Associated Health Risk. Environmental Geochemistry and Health, 25:307-323.
Manta, D.S., Angelone, M.,Bellanca A., Neri R., SprovienM. (2002). Heavy Metal in Urban Soils: Case Study from City Of Palermo (Sicily), Italy. Science of the Total Environment, 300:229-243.

Miller, W.P. and Mcfee, W.W. (1983). Distribution of Cd, $\mathrm{Zn}, \mathrm{Cu}$ and $\mathrm{Pb}$ in soils of industrial north-western Indiana. Journal of Environmental Qualty, 12, 29 33.

Odoh, R., Agbaji, E. B.,Kagbu, J. A., Thomas, S. A. (2011). Heavy Metal Speciation in Agricultural Farmland in Some Selected Local Government Areas of Benue State, Nigeria. Arch. Appl. Sci. Res., 3 (3): 560573.

Osakwe, S. A. (2010). Chemical Speciation and Mobility of Some Heavy Metals in Soils Around automobile waste Dumpsites in Northern Part of Niger Delta, South Central Nigeria. J. Appl. Sci. Environ. Manage., 14 (4): 123-130.

Rieuwerts, J. S., Searle, P., and Buck, R. (2006). Bioaccessible arsenic in the home environment in Southwest England. The science of the Total Environment, 371: 89-98.

Shuman, L.M. (1985). Fractionation method for Soil Microelements. Soil Science, 140, 11-22.

Tack, F.M.G. and Verloo, M.G. (1995). Chemical speciation and fractionation in soil and sediment heavy metal analysis: a review. Int. J. Environ. Anal. Chem. 59, 225-238. 70 Contents and main fractions of trace elements in TypicArgiudolls of the Argentinian Pampas.

Tessier, A., Campbell, P.G.C. and Bisson, N. (1979). Sequential extraction procedure for the speciation of particulate traces metals. Analytical Chemistry, 51(7): 844- 861.

Todorovi, Z., Poli, P., Djordjevi, D and Antoni J. S. (2001). Lead Distribution in Water and its Association with Sediment Constituents of the Barje Lake, Leskovar, Yugoslavia. Journal of Serbian Chemical Society, 66(1): 697-708.

Uba, S. Uzairu, A., Harrison, G. F. S., Balarabe, M.L. and Okunola, O. J. (2008). Assessment of Heavy Metals Bioavailability in Dumpsites of Zaria Metropolis. Journal of African Biotechnology, 7 (2), 122-130.

USEPA (1998). Toxicological Review of Hexavalent Chromium. Environmental Protection Agency.

Venkateswaran, P., Vellaichamy, S. and Palanivelu, K, (2007). Speciation of heavy metals in electroplating industry sludge and wastewater residue using inductively coupled plasma. International Journal of Environment and Science Technology, 4(4): 497 $-504$.

Wood, J.M. (1974). Biological Cycles for Elements in the Environmental Science 183(3-4), 211228.

Xian, X. (1989). Effect of chemical forms of cadmium, zinc and lead in polluted soil and their Uptake by cabbage plants and soil. Journal of Environmental Science and Health, 113, 257-264.

Yeung, Z.L.L., Kwok, R.C.W and Yu, K.N. (2003). Determination of Multi-Element Profiles of Street Dust Using Energy Dispersive X-ray Fluorescence (EDXRF), Appl. Radial. Isot. 58:339 346. 